\title{
MORFOANATOMIA FOLIAR DE CUPUAÇUZEIROS ESTABELECIDOS POR DIFERENTES MÉTODOS DE PROPAGAÇÃO E SOMBREAMENTO' ${ }^{1}$
}

\author{
DHEIMY SILVA NOVELLI ${ }^{2}$, SEBASTIÃO ELVIRO DE ARAÚJO NETO, \\ PAULO CÉSAR POETA FERMINO JUNIOR DA SILVA ${ }^{4}$, \\ RAFAELLA GEORGIA LIMA DAMASCENO 5 , IRENE FERRO DA SILVA ${ }^{6}$
}

RESUMO - O objetivo deste trabalho foi avaliar o efeito do sombreamento e de métodos de propagação na morfoanatomia foliar e no estabelecimento de cupuaçuzeiros. O experimento foi realizado a campo, em blocos casualizados, com quatro repetições de 10 plantas cada. Para análise de crescimento, utilizou-se do esquema de parcelas subsubdivididas (cinco épocas - parcela; três níveis de sombreamento - subparcela, e quatro métodos de propagação - subsubparcela). Para a avaliação da biometria das plantas, utilizou-se do esquema de parcela subdivida com os sombreamentos na parcela e os métodos de propagação nas subparcelas; e para as análises morfoanatômicas, considerou-se a casualização do sombreamento nos blocos. As análises de crescimento foram realizadas a cada 90 dias; e as morfoanatômicas, aos 15 meses após o plantio. A espessura do parênquima esponjoso foi maior nas folhas sombreadas por tela de $50 \%$, as outras características morfoanatômicas não sofreram influência significativa dos níveis de sombreamento. As mudas com desenvolvimento inicial em viveiro atingiram maior taxa de crescimento relativo e absoluto. As maiores taxas de crescimento relativo e absoluto foram obtidas em cultivo sob tela de $50 \%$ de sombreamento, seguido pelo consórcio ( $45 \%$ de sombreamento). Os piores desempenhos em todas as características avaliadas foram observados em plantas cultivadas a pleno sol.

Termos para indexação: Theobroma grandiflorum, Anatomia, Policultivo.

\section{MORPHOANATOMY LEAF OF CUPUASSU PLANT ESTABLISHED FOR DIFERENT METHODS OF SPREAD AND SHADOWING}

\begin{abstract}
The objective of this study was to evaluate the effect of shadowing and propagation methods in morphoanatomy and establishing cupuassu. The field experiment was conducted in a randomized complete block design with four replications of 10 plants each. For growth analysis was used to plot sub divided (five times - plot, three levels of shading - subplot and four methods of propagation - sub - subplots). For evaluation of biometrics plant was used scheme subdivides plot with shading in the plot and subplots propagation methods; and the analysis morphoanatomic considered the randomization in blocks of shading. Analyses of growth were performed every 90 days and morphoanatomical at 15 months after planting. The thickness of the spongy parenchyma was higher in shaded leaves by $50 \%$ screen; other features morphoanatomic suffered no significant influence of shading levels. Seedlings with initial development in nurseries reached higher relative growth rate and absolute. The highest relative growth rates and absolute were obtained in culture under $50 \%$ screen, followed by the consortium $(45 \%)$. The worst performers in all traits were observed in plants grown in full sun.
\end{abstract}

Index terms: Theobroma grandiflorum, Anatomy, polyculture.

\footnotetext{
1(Trabalho 205-14).Recebido em: 18-07-2014. Aceito para publicação em: 27-02-2015. Parte da dissertação de mestrado da primeira autor apresentada ao programa de Pós-graduação em Agronomia: Produção vegetal da UFAC.

${ }^{2}$ Engenheira Agrônoma, Mestre em Produção Vegetal, IFRO-RO. E-mail:dheimynovelli@ifro.edu.br

${ }^{3}$ Eng. Agr. Doutor em Fitotecnia, Universidade Federal do Acre. Campus Universitário BR 364 Km 4, Distrito Industrial, CEP 69920900, Rio Branco - Acre. E-mail: selviro2000@yahoo.com.br

${ }^{4}$ Biólogo, Doutor em Biotecnologia. Universidade Federal de Santa Catarina. E-mail:petabio@hotmail.com.

${ }^{5}$ Bióloga. Universidade Federal do Acre. E-mail: rafaellagd@gmail.com.

${ }^{6}$ Enga. Agra. Mestre em produção Vegetal. Universidade Federal do Acre. E-mail: daireneagro@hotmail.com
} 


\section{INTRODUÇÃO}

O cupuaçuzeiro (Theobroma grandiflorum (Willd. ex Spreng.) Schum.) é uma espécie frutífera amazônica, cultivada, principalmente, em consórcio com outras culturas em sistemas agroflorestais. Tem excelente potencial econômico devido à polpa extraída do fruto, que agrada pelo sabor agridoce e pelo aroma característico. Extrai-se também o óleo das amêndoas para a fabricação de alimentos e cosméticos, e a casca pode ser utilizada para a produção de artesanatos ou o reaproveitamento em compostagem (CARVALHO et al., 2004).

A propagação do cupuaçuzeiro é feita basicamente por sementes, principalmente, devido ao curto período juvenil, com início da frutificação no terceiro ano após o plantio, e a alta taxa de germinação. Deve-se considerar também que o plantio de espécies arbóreas diretamente no campo, sem a fase de viveiro, é promissor por possuir bom rendimento operacional e baixo custo (FERREIRA et al., 2009; SANTOS et al., 2012).

A radiação consiste no fator físico mais importante para o controle do desenvolvimento de espécies arbóreas jovens nas florestas tropicais (NIINEMETS, 2010), regula a sobrevivência e o estabelecimento dessas plantas (VALLADARES; NIINEMETS, 2008) e afeta as características morfoanatômicas foliares e fotossintéticas (KIM et al., 2011). Por necessitar de sombra em sua fase juvenil, o cultivo em consórcio é comumente aplicado ao cupuaçuzeiro, o que altera a quantidade de luz disponível devido ao sombreamento. Além do sombreamento, o consórcio aumenta o rendimento por área, conserva o solo, melhora o aproveitamento de luz, água e nutrientes, melhora a alimentação do agricultor e diminui o risco agrícola (PYPERS et al., 2011).

Atualmente, para o cultivo do cupuaçuzeiro na Amazônia, há necessidade de estudos que viabilizem um sistema de produção economicamente viável e ecologicamente correto. Alterar o sistema de plantio comumente utilizado para a espécie, como a semeadura direta ou o transplantio de plântulas pode facilitar a implantação de espécies florestais (FERREIRA et al., 2009). Além disso, é um dos princípios da agroecologia o baixo gasto energético (AZEVEDO; PELICIONI, 2012).

O objetivo deste trabalho foi avaliar o efeito do sombreamento e de métodos de propagação na morfoanatomia foliar e no estabelecimento de cupuaçuzeiros.

\section{MATERIAL E MÉTODOS}

O experimento foi realizado no Sítio Ecológico Seridó, município de Rio Branco - AC, latitude de 9 53 ' $16^{\prime \prime} \mathrm{S}$ e longitude de $67^{\circ} 49^{\prime} 11^{\prime \prime} \mathrm{W}$, altitude de $170 \mathrm{~m}$, instalado no mês de março de 2012 e com duração de 15 meses. Nessa região amazônica, o clima é equatorial (Am) pela classificação de Köppen, quente e úmido, com temperatura média anual de $24,5{ }^{\circ} \mathrm{C}$, com máxima de $32{ }^{\circ} \mathrm{C}$, altos índices pluviométricos que variam de $1.600 \mathrm{~mm}$ a $2.750 \mathrm{~mm}$ anuais, com duas estações, sendo estas seca (maio a outubro) e chuvosa (novembro a abril) . Durante o experimento, a temperatura média foi de $27,2{ }^{\circ} \mathrm{C}$, a UR de $91,1 \%$ e a luminosidade de 192,6 horas/mês.

A área experimental é de topografia suavemente ondulada, e o solo, classificado como Argissolo Amarelo alítico plíntico, sem erosão aparente, de drenagem moderada. Os valores da análise de solo foram determinados na camada de $0-20 \mathrm{~cm}$ de profundidade, conforme manual de métodos da Embrapa (1997) e são: $\mathrm{pH}\left(\mathrm{H}_{2} \mathrm{O}\right)=5,1$; $\mathrm{P}=2 \mathrm{mg} \mathrm{dm}^{-3} ; \mathrm{K}=0,18 \mathrm{cmolc} \mathrm{dm}^{-3} ; \mathrm{Ca}=1,9 \mathrm{cmolc}$ $\mathrm{dm}^{-3} ; \mathrm{Mg}=0,9$ cmolc $\mathrm{dm}^{-3} ; \mathrm{Al}=0,8$ e $\mathrm{H}=0,64$ cmolc $\mathrm{dm}^{-3}$; matéria orgânica $=17 \mathrm{~g} \mathrm{dm}^{-3}$; saturação de bases $=29 \% ; \mathrm{Fe}=530 \mathrm{mg} \mathrm{dm}^{-3} ; \mathrm{Cu}=1,6 \mathrm{mg}$ $\mathrm{dm}^{-3} ; \mathrm{Mn}=99 \mathrm{mg} \mathrm{dm}^{-3} ; \mathrm{Zn}=2,6 \mathrm{mg} \mathrm{dm}^{-3}$, e B = $0,17 \mathrm{mg} \mathrm{dm}^{-3}$.

O experimento consistiu no estabelecimento de plantas de cupuaçuzeiro provenientes de cruzamento livre, sob três níveis de sombreamento: consórcio (abacaxi - Ananas comosus, variedade Smooth Cayenne, cv. Rio Branco 1; mandioca Manihot esculenta, cv. Manteguinha, e bananeira Musa sp. genoma AAAB cv. Pacovan Ken), tela de $50 \%$ de sombreamento e pleno sol. Também foram avaliados quatro métodos de propagação: semeadura direta; a lanço com proteção das sementes pela casca dos frutos; transplantio de plântula; e transplantio de mudas produzidas em viveiro, sendo avaliadas em cinco tempos diferentes (após 90; 180;270; 360 e 450 dias do plantio).

O abacaxi e a mandioca foram plantados em setembro de 2012. O abacaxizeiro foi cultivado em linhas triplas, no espaçamento de $0,80 \mathrm{~m} \times 0,25 \mathrm{~m}$ $\mathrm{x} 0,25 \mathrm{~m}$, com 2,0 $\mathrm{m}$ entre as ruas; a mandioca foi cultivada a $0,20 \mathrm{~m}$ das linhas externas do abacaxi, em espaçamento de 1,0 m x 1,0 m; e a bananeira, plantada em abril de 2012, no espaçamento de $4 \mathrm{~m}$ x $4 \mathrm{~m}$.

Frutos de cupuaçuzeiro foram coletados após sua queda natural, na véspera da instalação do experimento, e despolpados mecanicamente, e as 
sementes retiradas foram semeadas nos três níveis de sombreamento e acondicionadas em sulco e a lanço, com o uso de cascas dos frutos cortados ao meio como protetor para as sementes, em sacolinhas, no viveiro e também a campo, plântulas com aproximadamente $7,0 \mathrm{~cm}$ de altura.

Utilizou-se de 50 sementes por repetição em cada tratamento e, após 30 dias de semeio, foi feito o raleio, mantendo-se 16 plantas por repetição em todos os tratamentos.

O delineamento experimental foi em o blocos casualizados, em parcelas sub-subdivididas, sendo as parcelas as cinco épocas de avaliação, as subparcelas os três níveis de sombreamento e os quatro métodos de plantio as subsubparcelas, com quatro repetições.

Foi utilizado luxímetro modelo C.A 810 (lux/ $\left.\mathrm{m}^{2}\right)$ para aferir os níveis de intensidade luminosa dos sombreamentos em horários preestabelecidos: $10 \mathrm{~h}, 12 \mathrm{~h}, 14 \mathrm{~h}$ e $15 \mathrm{~h} 30$. Os níveis de sombreamento foram definidos e a porcentagem, ficando o pleno sol com $0 \%$, o consórcio com $45 \%$ e a tela com $50 \%$ de sombra.

Foram retiradas 30 folhas do terceiro nó, por tratamento, de plantas identificadas para as análises anatômicas, realizadas no Laboratório de Tecidos Vegetais da Universidade Federal do Acre.

Lâminas semipermanentes foram confeccionadas à mão livre através de secções paradérmicas e transversais da lâmina foliar, com auxílio de lâmina de aço, e coradas com safranina (BUKATSCH, 1972). As lâminas foram observadas em microscópio óptico e as imagens, projetadas com auxílio de câmara clara acoplada. As estruturas morfométricas foram aferidas com escala micrométrica.

As avaliações anatômicas foram realizadas através das medições do comprimento do feixe vascular (CFV), da morfometria de estômatos [comprimento $(\mathrm{CCG})$ e da largura das célulasguarda (ECG), do comprimento (CPE) e da largura do poro estomático(EPE)], da espessura da epiderme da face adaxial (EEAD) e abaxial (EEAB), dos parênquimas paliçádico (EPP) e esponjoso (EPE), da densidades de tricomas (DT) e de estômatos (DE). Para cada parâmetro morfométrico, foram realizadas três repetições com dez estruturas cada.

Das análises estatísticas realizadas, foram verificadas a presença de dados discrepantes, pelo teste de Grubbs,;a verificação da normalidade dos resíduos, pelo teste de Shapiro-Wilk; a verificação da homogeneidade de variâncias, pelo teste de Bartlett; a comparação das médias, pelo teste de Tukey $(\mathrm{p}<0,05)$ para os tratamentos qualitativos, e análise de regressão, para as variáveis quantitativas.

\section{RESULTADOS E DISCUSSÃO}

$\mathrm{O}$ cupuaçuzeiro mostrou-se sensível à radiação, pois quando se excluiu o sombreamento, as mudas tiveram redução na taxa de crescimento relativo (TCR) (Figura 1) e na taxa de crescimento absoluto (TCA) (Figura 2). Espécies fotolábeis podem sofrer danos quando são expostas à radiação (TAIZ; ZEIGER, 2013; LARCHER, 2004). A TCR, no cultivo a pleno sol, está vinculada ao estágio sucessional da espécie avaliada, tendendo as pioneiras e intermediárias a apresentarem desempenho superior em comparação às secundárias e ao clímax (SOUZA; VÁLIO, 2003). Araújo et al. (2012) observaram que o maior crescimento de mudas sombreadas de Baru (Dipteryx alata Vog.) ocorre pela maior fotossíntese líquida.

A TCA reduziu em $0,002139 \mathrm{~cm}^{2} \mathrm{dia}^{-1}$ nas plantas cultivadas a pleno sol (Figura 2). Observouse redução no crescimento absoluto também para plantas cultivadas sob tela de $50 \%$ e em consórcio, até aos 199 e 281 dias, respectivamente, retornando o crescimento a partir desse período. Este fato pode ser explicado pelos baixos índices pluviométricos no período, assim as mudas produzidas no viveiro não sofreram redução na TCA devido à irrigação que recebiam.

A condição estressante a que as mudas a campo sofreram pode ter induzido a senescência das folhas e contribuído para a redução da TCA. Larcher (2004) afirma que, em espécies perenes, a senescência das folhas inicia-se comumente devido a fatores externos, como dias curtos, limites de temperatura e outras situações estressantes à planta.

A TCA das mudas com período inicial em viveiro foi linear, com acúmulo de 0,006837 $\mathrm{cm}^{2} \mathrm{dia}^{-1}$, e as plantas crescidas diretamente no campo apresentam redução da TCA até aos 235 ; 268 e 282 dias, respectivamente, para semeadura a lanço, plantio direto e plântula (Figura 3). O período de redução da TCA, nos três métodos de estabelecimento a campo, coincide com o decréscimo dos índices pluviométricos e o aumento da insolação, devendo-se, portanto, a estes fatores ambientais a diminuição no crescimento das plantas.

O uso de plântulas proporcionou a maior redução na TCA, em razão da fase considerada de particular sensibilidade das plantas devido ao rápido crescimento, necessitando de suprimentos, como água, nutrientes e luz adequados (LARCHER, 2004); assim sendo, a brusca mudança nesses 
fatores ambientais, quando levadas a campo, pode ter provocado a diminuição da TCA.

Menor TCA também ocorreu em Gallesia integrifólia, que paralisou o crescimento nos primeiros 90 dias após o transplantio das mudas a pleno sol e 60 dias em 45 e $90 \%$ de sombra (DEMUNER et al., 2004), devido à acentuada mudança nas condições de luz. Em plântulas de Euperte edulis Mart., a sobrevivência inicial em clareira e sub-bosque em fragmentos de uma Floresta Estacional Semidecidual foi negativa; neste caso, afetada pela baixa disponibilidade hídrica (RIBEIRO et al., 2011).

O melhor desempenho das mudas crescidas em viveiro deve-se ao controle de fatores como temperatura, luminosidade e umidade, que favorece o acúmulo de biomassa das plantas (PEGORARO et al., 2010).

O cupuaçuzeiro sombreado com tela de $50 \%$ teve maior TCA quando propagado a lanço e em mudas de viveiro, sendo semelhante ao consórcio quando propagadas por plantio direto e transplantio de plântulas, ambos superiores ao ambiente a pleno sol (Tabela 1).

No consórcio, não houve diferença da taxa de crescimento entre o plantio direto, plântulas e mudas de viveiro, que foram superiores à propagação a lanço. São nestas condições que o cupuaçuzeiro é encontrado na natureza (CARVALHO et al., 2004).

O mesofilo de folhas cultivadas a pleno sol possui duas camadas de células do parênquima paliçádico (Figura 4) com pequenos espaços intercelulares, enquanto as folhas sombreadas apresentam apenas uma (Figura 4). Entretanto, não houve diferença significativa $(p<0,05)$ na espessura do parênquima paliçádico (Tabela 2).

Em folhas de sol, a espessura da lâmina é reforçada pelo alongamento adaxial/abaxial das células parenquimáticas ou pela adição de uma camada do parênquima paliçádico (TOMÁS et al., 2013). Essa organização visa a favorecer a difusão de $\mathrm{CO}_{2}$ para os processos fotossintéticos. Dentro das folhas, o $\mathrm{CO}_{2}$ apresenta duas fases de vias de difusão, sendo a fase líquida celular (parede celular, membrana plasmática, citosol, membranas dos cloroplastos e estroma) a mais influente (TOMÁS et al., 2013). Nesse sentido, o aumento de superfície das células do parênquima paliçádico em folhas expostas a maior luminosidade facilita a exposição dos cloroplastos ao gás carbônico, aumentando a atividade fotossintética (TERASHIMA et al., 2011). $\mathrm{O}$ expressivo aumento do parênquima paliçádico e da espessura foliar, sob alta radiação, indica uma grande habilidade na captura da luz, uma estratégia associada com a tolerância à sombra (EVANS; POORTER, 2001).

O parênquima esponjoso apresenta células com aspecto mais globoso e espaços intercelulares conspícuos (Figuras 4A e 4B). A espessura do parênquima esponjoso foi maior quanto maior o percentual de sombreamento (Tabela 2). De acordo com Terashima et al. (2011), o parênquima esponjoso possibilita o espalhamento da radiação luminosa e facilita a difusão lateral do $\mathrm{CO}_{2}$ a partir das câmaras subestomáticas.

A face abaxial das folhas de cupuaçuzeiro apresenta tricomas do tipo estrelado e glandular, além dos estômatos esparsamente distribuídos, sendo a espécie classificada como hipoestomática (FERREIRA et al., 2008). A espessura da epiderme nas faces abaxial e adaxial não apresentou variações significativas $(p<0,05)$ entre os níveis de sombreamento avaliados (Tabela 2). A epiderme é um tecido com funções múltiplas, dentre elas atua como uma barreira para a penetração da luz solar (DICKISON, 2000; JAVELLE et al., 2011).

As dimensões e a densidade estomática não apresentaram variações significativas $(p<0,05)$ entre os tratamentos. A quantidade, a distribuição, o tamanho e o formato dos estômatos são características inerentes a cada espécie e podem ou não ser modificadas em função das adaptações às condições ambientais, como disponibilidade de radiação solar (DICKISON, 2000). A ausência de variações significativas nas características estomáticas de folhas de cupuaçuzeiro em diferentes níveis de sombreamento deve influenciar nas relações hídricas da espécie em condições de maior luminosidade, aumentando a transpiração e reduzindo a taxa de crescimento absoluto (SCHOCK et al., 2013). 


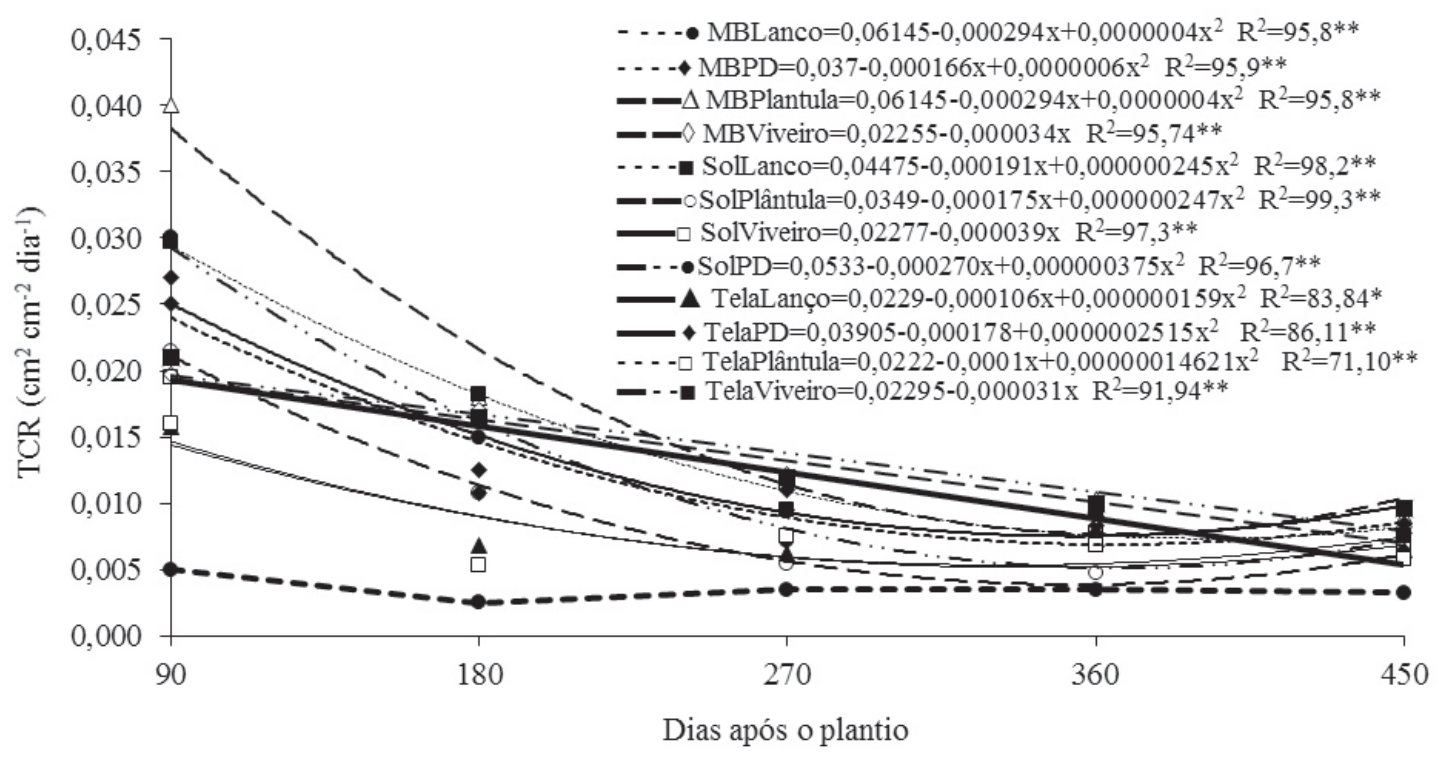

FIGURA 1 - Taxa de crescimento relativo (TCR) de mudas de cupuaçuzeiro sombreadas por consórcio, tela de $50 \%$ e a pleno sol, em plantio a lanço, direto, plântulas e mudas de viveiro, em Rio Branco-Acre.

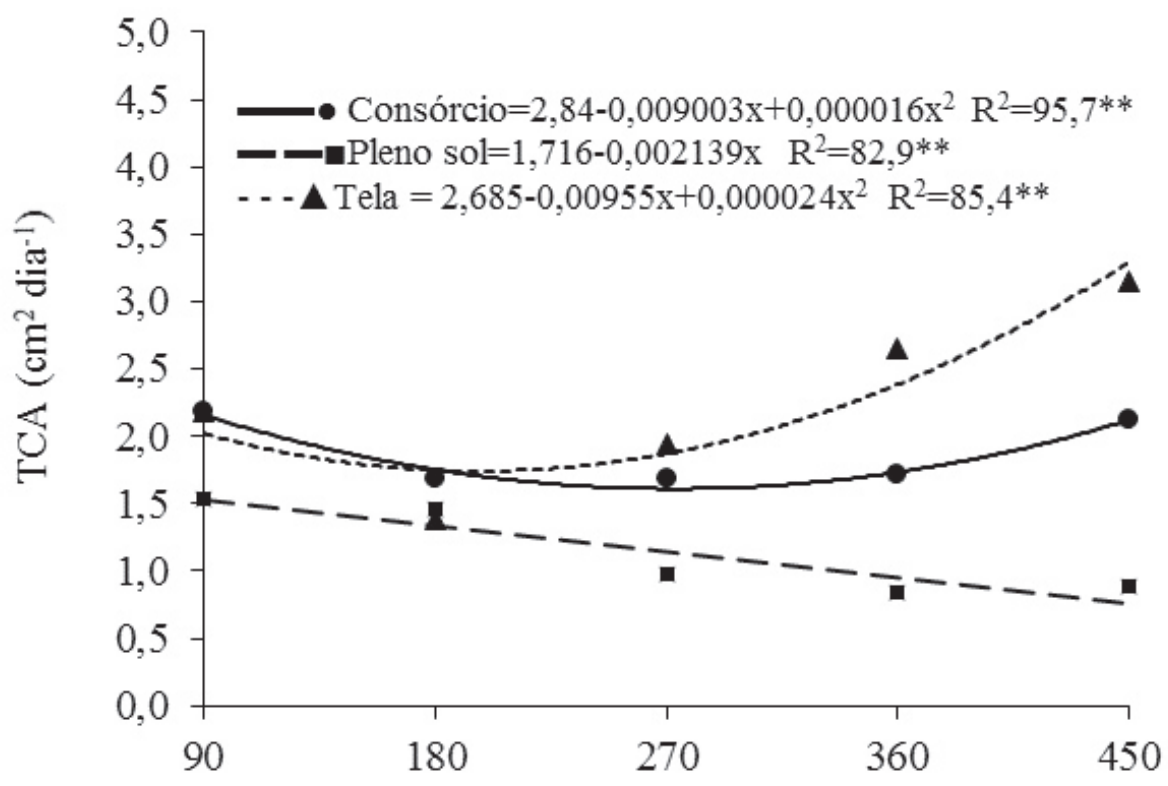

Dia após o plantio

FIGURA 2 - Taxa de crescimento absoluto (TCA) de mudas de cupuaçuzeiro sob consórcio, tela $50 \%$ e pleno sol, em Rio Branco-Acre. 


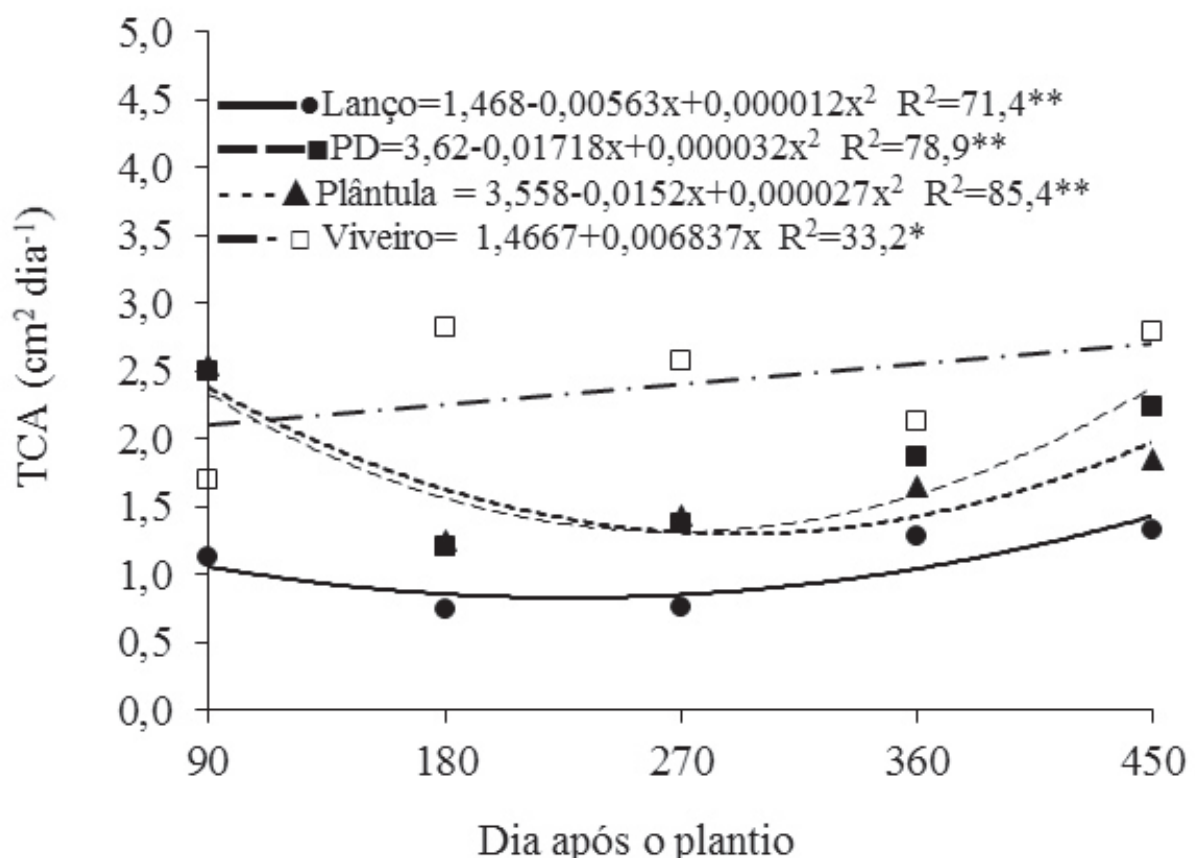

FIGURA 3 - Taxa de crescimento absoluto (TCA) de mudas de cupuaçuzeiro em plantio direto, a lanço, transplantio de plântulas e mudas, em Rio Branco-Acre.

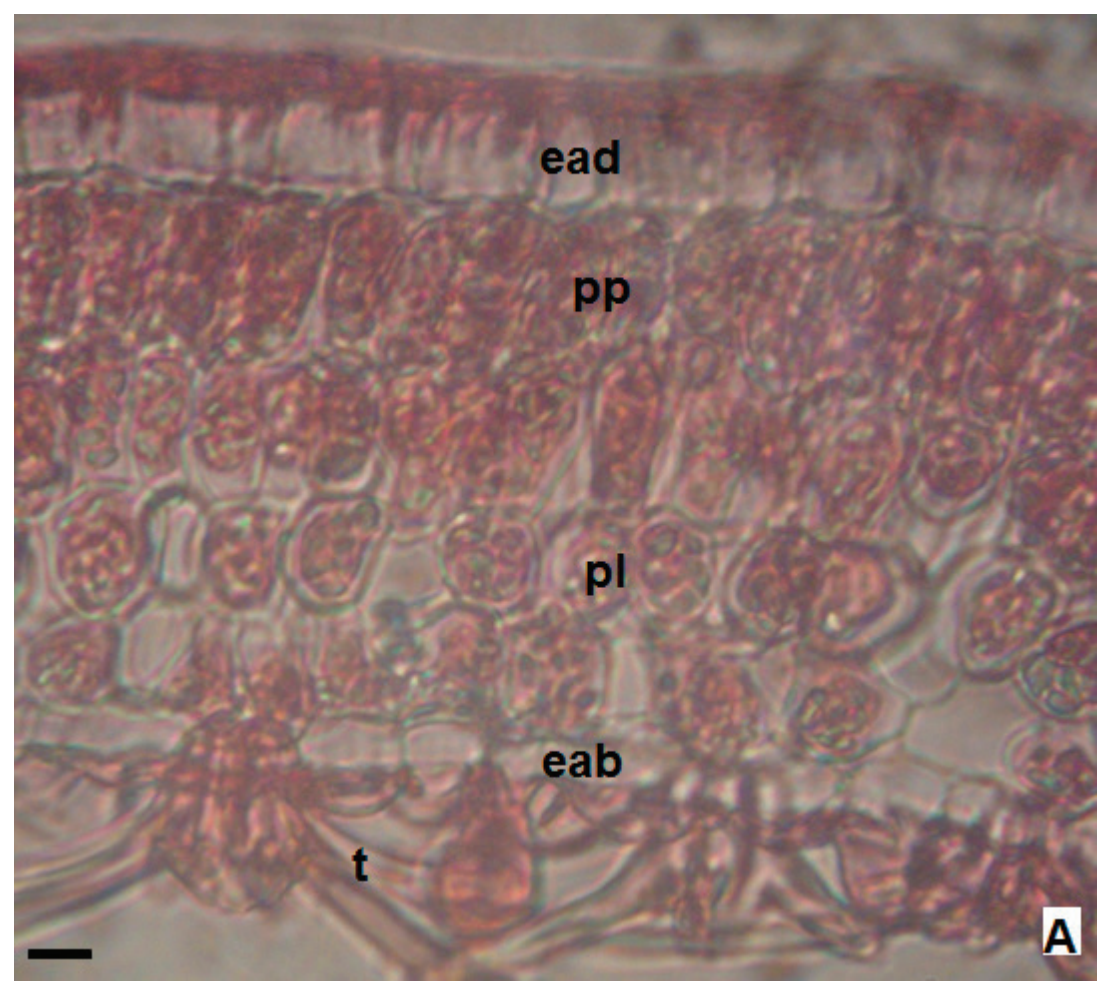

FIGURA 4 - Secção transversal da lâmina foliar do cupuaçuzeiro. Aspecto geral da região mediana de plantas cultivadas a pleno sol (A); Aspecto geral da região mediana de plantas cultivadas à sombra (B). Epiderme adaxial (ead), epiderme abaxial (eab), parênquima paliçádico (pp), parênquima esponjoso (pe), tricoma estrelado (t). Barra $=10 \mu \mathrm{m}$. 
TABELA 1 - Taxa de Crescimento Absoluto (TCA) de mudas de cupuaçuzeiro, sob tela de 50\%, consórcio e pleno sol em plantio direto (PD), a lanço, transplantio de plântulas e mudas de viveiro, em Rio Branco-Acre.

\begin{tabular}{cccc}
\hline Plantio & \multicolumn{3}{c}{ Sombreamento } \\
& $0 \%$ (pleno sol) & $45 \%$ (consórcio) & $50 \%$ (telado) \\
\hline Lanço & $0,74 \mathrm{bB}$ & $0,83 \mathrm{bB}$ & $1,58 \mathrm{cA}$ \\
PD & $0,95 \mathrm{bB}$ & $2,09 \mathrm{aA}$ & $2,19 \mathrm{bA}$ \\
Plântula & $1,01 \mathrm{bB}$ & $2,11 \mathrm{aA}$ & $2,43 \mathrm{bA}$ \\
Viveiro & $1,87 \mathrm{aC}$ & $2,48 \mathrm{aB}$ & $2,87 \mathrm{aA}$ \\
\hline CV\% & 35,05 & 27,16 & 27,52 \\
\hline
\end{tabular}

Médias seguidas de mesma letra, minúsculas nas colunas e maiúsculas na linha, não diferem entre si, pelo teste de Tukey, a $5 \%$ de probabilidade.

TABELA 2 - Comprimento (CCG) e largura das células-guarda (LCG), comprimento (CP) e largura do poro estomático (LP), espessura da epiderme adaxial (EEAD), espessura do parênquima paliçádico (EPP), espessura dos parênquima esponjoso (EPE), espessura da epiderme abaxial (EEAB), espessura do feixe vascular (EFV), densidade de estômatos (DE) e densidade de tricomas (DT) de folhas de cupuaçuzeiro, aos 15 meses de idade, cultivadas em consórcio, a pleno sol e sob tela de 50\%, em Rio Branco- Acre.

\begin{tabular}{lrrrr}
\hline \multicolumn{1}{c}{ Variáveis } & \multicolumn{4}{c}{ Sombreamento } \\
\hline C\% (pleno sol) & $45 \%$ (consórcio) & $\begin{array}{c}50 \% \\
\text { (telado) }\end{array}$ & CV\% \\
\hline CCG $(\mu \mathrm{m})$ & $16,61 \mathrm{a}$ & $15,63 \mathrm{a}$ & $15,55 \mathrm{a}$ & 3,3 \\
LCG $(\mu \mathrm{m})$ & $6,01 \mathrm{a}$ & $5,92 \mathrm{a}$ & $6,28 \mathrm{a}$ & 6,2 \\
CP $(\mu \mathrm{m})$ & $7,88 \mathrm{a}$ & $7,32 \mathrm{a}$ & $7,24 \mathrm{a}$ & 5,5 \\
LP $(\mu \mathrm{m})$ & $5,05 \mathrm{a}$ & $5,07 \mathrm{a}$ & $4,61 \mathrm{a}$ & 7,3 \\
EEAD $(\mu \mathrm{m})$ & $15,08 \mathrm{a}$ & $14,54 \mathrm{a}$ & $15,45 \mathrm{a}$ & 7,6 \\
EPP $(\mu \mathrm{m})$ & $31,29 \mathrm{a}$ & $30,74 \mathrm{a}$ & $30,86 \mathrm{a}$ & 7,0 \\
EPE $(\mu \mathrm{m})$ & $36,15 \mathrm{c}$ & $38,94 \mathrm{~b}$ & $41,28 \mathrm{a}$ & 6,4 \\
EEAB $(\mu \mathrm{m})$ & $8,02 \mathrm{a}$ & $7,52 \mathrm{a}$ & $7,72 \mathrm{a}$ & 6,5 \\
EFV $(\mu \mathrm{m})$ & $425,15 \mathrm{a}$ & $441,65 \mathrm{a}$ & $484,15 \mathrm{a}$ & 6,2 \\
DE $\left(\mathrm{n}^{\circ} . \mathrm{mm}^{-1}\right)$ & $8,57 \mathrm{a}$ & $7,46 \mathrm{a}$ & $7,58 \mathrm{a}$ & 6,7 \\
DT $\left(\mathrm{n}^{\circ} . \mathrm{mm}^{-1}\right)$ & $9,64 \mathrm{a}$ & $9,21 \mathrm{a}$ & $8,35 \mathrm{a}$ & 8,4 \\
\hline
\end{tabular}

$\mathrm{n}=60$ para cada variável.

Médias seguidas de mesma letra, nas linhas, não diferem entre si, pelo teste de Tukey, a 5\% de probabilidade.

\section{CONCLUSÕES}

A maior taxa de crescimento absoluto em plantas de cupuaçuzeiro no estabelecimento da cultura é obtida pelos métodos de propagação de mudas em recipiente com fase de viveiro seguido por semeadura direta a campo.

Ao final do estabelecimento, a maior taxa de crescimento absoluto é obtida com mudas de viveiro e ambiente sombreado com tela de $50 \%$.
$\mathrm{O}$ aumento da luminosidade proporciona aumento do número de camadas do parênquima paliçádico e redução na espessura do parênquima esponjoso. As características estomáticas não sofrem alterações em maior luminosidade e devem estar associadas com a menor taxa de crescimento absoluto. 


\section{REFERÊNCIAS}

ARAÚJO, A. C.; AJALLA, E. V.; VIEIRA, M. C.; ZÁRATE, N. A. H. Produção de mudas

de baru (Dipteryx alata Vog.) sob três níveis de sombreamento e quatro classes texturais de solo. Revista brasileira de fruticultura, Jaboticabal, v. 34, n.3, p. 888-896, 2012.

AZEVEDO, E.; PELICIONI, M. C. F. Agroecologia e promoção da saúde no Brasil. Revista Panamericana de Salud Publica, Washington, v. 31, n.4, p. 290-5. 2012.

BUKATSCH, F. Bemerkungen zur Doppelfarbung Astrablau-Safranin. Mikrokosmos, Berlin, v.61, n. 8, p. $255,1972$.

CARVALHO, J. E. U. de; MÜLLER, C. H.; ALVES, R. M.; NAZARÉ, R. F. R. de Cupuaçuzeiro. Belém, PA: Embrapa Amazônia Oriental, 2004. (Comunicado Técnico, 115).

DEMUNER, V.G.;HEBLING, S.A.;DAGUSTINHO, D. M. Efeito do sombreamento no crescimento inicial de Gallesia integrifolia (Spreng.) Harms. Boletim do Museu de Biologia Mello Leitão, Santa Teresa, ES, n. 17, p.45-55, jul. 2004.

DICKISON, W. Integrative Plant Anatomy. Harcourt Academic Press. USA. 2000. 548p.

EMBRAPA- Empresa Brasileira de Pesquisa Agropecuária. Centro Nacional de Pesquisa de Solos. Manual de métodos de análise de solos. 2. ed. Rio de Janeiro: EMBRAPA-CNPS, 1997. 212 p.

EVANS, J. R.; POORTER, H. Photosynthetic acclimation of plants to growth irradiance: the relative importance of specific leaf area and nitrogen partitioning in maximizing carbon gain. Plant, Cell and Environment, Malden, v.24, p.755-767, 2001.

FERREIRA, M. G. R.; NOGUEIRA, A. E.; DAMIÃO FILHO, C. F. Morfologia foliar de Theobroma grandiflorum Schum. Ciência Rural, Santa Maria, v.38, n.2, p.530-533, 2008.
FERREIRA, R. A.; SANTOS, P. L.; ARAGÃO, A. G.; SANTOS, T. I. S.; SANTOS NETO, E. M.; REZENDE, A. M. S. Semeadura direta com espécies florestais na implantação de mata ciliar no Baixo São Francisco em Sergipe. Scientia Forestalis, Piracicaba, v. 37, n. 81, p. 037-046, 2009.

JAVELLE, M.; VERNOUD, V.; ROGOWSKY, P.M.; INGRAM, G.C. Epidemis: the formation and functions of a fundamental plant tissue. New Phytologist, Lancaster, v.189, n.1, p.17-39, 2011.

KIM S. J.; YUA D. J.; KIMB T.C.; LEE H. J. Growth and photosynthetic characteristics of blueberry (Vaccinium corymbosum cv. Bluecrop) under various shade levels. Scientia Horticulturae, Amsterdam, v. 29, p. 486-492, 2011.

LARCHER, W. Ecofisiologia vegetal. São Carlos: Rima, 2004. 355 p.

NIINEMETS, U. A review of light interception in plant stands from leaf to canopy in different plant functional types and in species with varying shade tolerance. Ecological Research, Tokyo, v.25, p.693714, 2010.

PEGORARO, R. L.; FALKENBERG, M. B.; VOLTOLINI, C. H.; SANTOS, M.; PAULILO, M. T. S. Produção de óleos essenciais em plantas de Mentha x piperita L. var. piperita (Lamiaceae) submetidas a diferentes níveis de luz e nutrição do substrato. Revista Brasileira de Botânica, São Paulo, v.33, n.4, p.631-637, 2010.

PYPERS, P.; SANGINGAB, J. M.; KASEREKAB, B.; WALANGULULUC, M.; VANLAUWEA, B. Increased productivity through integrated soil fertility management in cassava-legume intercropping systems in the highlands of Sud-Kivu, DR Congo. Fields Crops Research, Amsterdam, v. 120, n. 1, p. 76-85, 2011

RIBEIRO, T. M.; MARTINS, S. V.; LANA, V. M.; SILVA, K. A. Sobrevivência e crescimento inicial de plântulas de Euterpe edulis Mart. transplantadas para clareiras e sub-bosque em uma floresta estacional semidecidual, em Viçosa, MG. Revista Árvore, Viçosa,MG, v.35, n.6, p.1219-1226, 2011. 
SANTOS, P. L.; FERREIRA, R. A.; ARAGÃO, A. G.; AMARAL, L. A.; OLIVEIRA, A. S. Estabelecimento de espécies florestais nativas por meio de semeadura direta para recuperação de áreas degradadas. Revista Árvore, Viçosa, v.36, n.2, p.237-245, 2012.

SCHOCK, A.A.; RAMM, A.; MARTINAZZO, E.G.; SILVA, D.M.; BACARIN, M.A. Crescimento e fotossíntese de plantas de pinhão-manso cultivadas em diferentes condições de luminosidade. Revista Brasileira de Engenharia Agrícola e Ambiental, Campina Grande, v.18, n.1, p.3-9, 2014.

SOUZA, R. P.; VÁLIO, I. F. M. Seedling growth of fifteen Brazilian tropical tree species differing in successional status. Revista Brasileira de Botânica, São Paulo, v.26, n.1, p. 35-47, 2003.

TAIZ, L.; ZEIGER, E. Fisiologia vegetal. 5. ed. Porto Alegre: ArtMed, 2013.
TERASHIMA, I.; HANBA, Y.T.; THOLEN, D.; NIINEMETS, U. Leaf functional anatomy in relation to photosynthesis. Plant Physiology, Waterbury, v.155, n.1, p.108-116, 2011.

TOMÁS, M.; FLEXAS, J.; COPOLOVICI, L.; GALMÉS, J.; HALLIK, L.; MEDRANO, H.; RIBAS-CARBÓ, M.; TOSENS, T.; VISLAP, V.; NIINEMETS, U. Importance of leaf anatomy in determining mesophyll diffusion conductance to $\mathrm{CO}_{2}$ across species: quantitative limitations and scaling up by models. Journal of Experimental Botany, Oxford, v.64, n.8, p.2269-2281, 2013.

VALLADARES, F; NIINEMETS, U. Shade tolerance, a key plant feature of complex nature and consequences. Annual Review of Ecology, Evolution and Systematics, Palo Alto,v. 39, p.237-257, 2008. 